\title{
ASO Visual Abstract: Prediction of Pathologic Complete Response in Breast Cancer Patients Comparing Magnetic Resonance Imaging with Ultrasound in the Neoadjuvant Setting
}

\author{
Frederik Knude Palshof ${ }^{1}$ (D), Charlotte Lanng, MD $^{2}$, Niels Kroman, DMSc ${ }^{2}$, Cemil Benian, MD $^{3}$, \\ Ilse Vejborg, $\mathrm{MD}^{3}$, Anne Bak, $\mathrm{MD}^{4}$, Maj-Lis Talman, $\mathrm{MD}^{5}$, Eva Balslev, $\mathrm{MD}^{6}$, \\ and Tove Filtenborg Tvedskov, DMSc ${ }^{2}$
}

${ }^{1}$ University of Copenhagen, Copenhagen, Denmark; ${ }^{2}$ Department of Breast Surgery, Rigshospitalet/Herlev-Gentofte Hospital, Copenhagen University Hospital, Copehagen, Denmark; ${ }^{3}$ Department of Radiology, Rigshospitalet, Copenhagen University Hospital, Copenhagen, Denmark; ${ }^{4}$ Department of Radiology, Herlev Hospital, Copenhagen University Hospital, Herlev, Denmark; ${ }^{5}$ Department of Pathology, Rigshospitalet, Copenhagen University Hospital, Copenhagen, Denmark; ${ }^{6}$ Department of Pathology, Herlev Hospital, Copenhagen University Hospital, Herlev, Denmark

Precise imaging is crucial when planning surgery in the breast after neoadjuvant chemotherapy. We found magnetic resonance imaging to be more specific than ultrasound in predicting pathologic complete response in women with breast cancer (https://doi.org/10.1245/s10434021-10117-8).

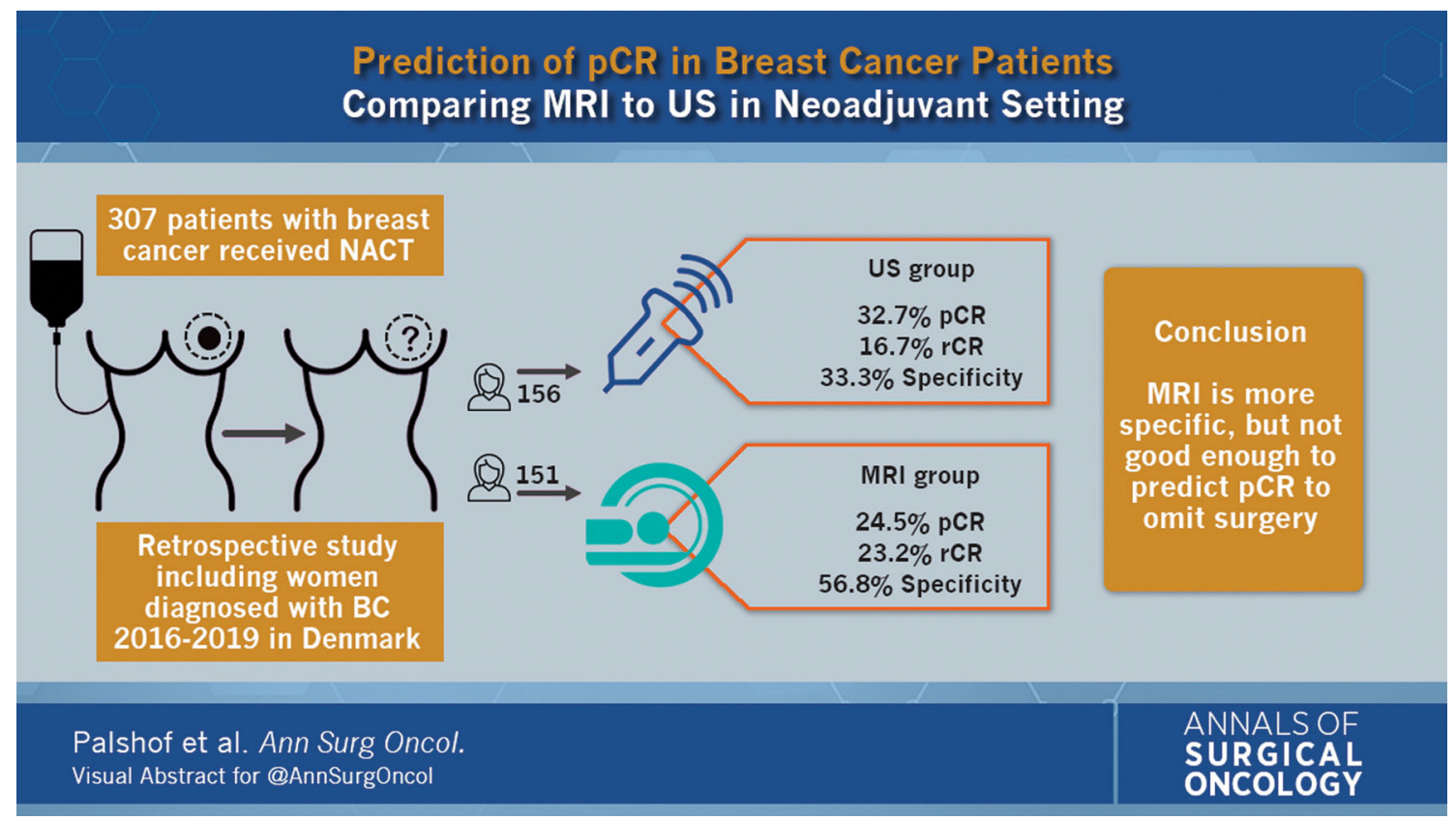

(C) Society of Surgical Oncology 2021

Published Online: 21 May 2021

F. K. Palshof

e-mail: frederik.knude.palshof.01@ regionh.dk;

Publisher's NoteSpringer Nature remains neutral with regard to frederikpalshof@gmail.com jurisdictional claims in published maps and institutional affiliations. 